\title{
Water Availability Footprint Addressing Water Quality
}

\section{Xuexiu Jia ${ }^{*}$, Petar S. Varbanov ${ }^{2}$, Jiři J. Klemeš ${ }^{3}$, Sharifah R. Wan Alwi ${ }^{4}$}

${ }^{1}$ Sustainable Process Integration Laboratory, NETME Centre, Faculty of Mechanical Engineering, Brno University of Technology, Technická 2896/2, 616 00, Brno, Czech Republic e-mail: jia@fme.vutbr.cz

${ }^{2}$ Sustainable Process Integration Laboratory, NETME Centre, Faculty of Mechanical Engineering, Brno University of Technology, Technická 2896/2, 616 00, Brno, Czech Republic

\author{
e-mail: varbanov@fme.vutbr.cz
}

${ }^{3}$ Sustainable Process Integration Laboratory, NETME Centre, Faculty of Mechanical Engineering, Brno University of Technology, Technická 2896/2, 616 00, Brno, Czech Republic e-mail: jiri.klemes@vutbr.cz

${ }^{4}$ Process Systems Engineering Centre (PROSPECT), Research Institute for Sustainable Environment and Faculty of Chemical and Energy Engineering, University of Technology, 81310 UTM Johor Bahru, Johor, Malaysia e-mail: syarifah@utm.my

Cite as: Jia, X., Varbanov, P. S., Klemeš, J. J., Wan Alwi, S. R., Water Availability Footprint Addressing Water Quality, J. sustain. dev. energy water environ. syst., 7(1), pp 72-86, 2019, DOI: https://doi.org/10.13044/j.sdewes.d6.0223

\begin{abstract}
The increasing issue of water quality degradation has affected the availability of water. The consideration of water quality is becoming more important for water minimisation. There is a need to integrate water quality into the current water assessment framework. This study tries to involve the water quality into the widely used water footprint assessment framework in order to quantify the water usability changes during the water use process. Based on water footprint concepts from international standard ISO 14046, water availability is further interpreted to emphasize the impact of water quality on the usability. An effective water availability footprint is defined as the quantitative and qualitative extent of a certain body of water which meets the needs of a certain purpose of water use. A water quality index is proposed to quantify the contribution of water quality on water availability, and two approaches of calculating water quality index are discussed, in order to explore the possibility of involving water quality into the water availability footprint assessment. Based on the definitions and framework, a case study is conducted to illustrate the features of this framework, and 3 outflows with different water quality are set to discuss the impact of different water quality profiles on the calculation of water availability footprint. It shows that water quality profiles can have a remarkable influence on the calculation. For the case with an outflow of $F_{2-1}$, the water availability footprints with minimum water quality index, average water quality index and the volumetric water footprints as $1,600 \mathrm{~m}^{3}, 1,277 \mathrm{~m}^{3}$, and $1,000 \mathrm{~m}^{3}$. This indicator can determine the consumptive water use and also quantify the exploitation of water quality. The involvement of water quality regarding multiple contaminants in water footprint assessment should be further investigated in future studies.
\end{abstract}

\section{KEYWORDS}

Water availability, Water footprint, Water quality, Water use, Water resource management.

\footnotetext{
* Corresponding author
} 


\section{INTRODUCTION}

Water is essential for life on this planet. However, with the rapid growth of the economy, urban population, as well as the changes of land use, water shortage and degradation have become severe issues and have generated a wide concern. Although water shortage was mainly considered in terms of quantity, the impact of water quality degradation is becoming more serious. In other words, the shortage of water is essentially a lack of clean water. Natural water supplies require pre-treatment before water use, discharge or recycle/reuse processes [1], which also means an increase of the economic cost to obtain a high-quality water supply/discharge [2].

Since the very early stages, indices such as the Falkenmark Indicator (FI) [3], Social Water Stress Index (SWSI) [4] and Water Poverty Index (WPI) [5] have been developed to quantify water shortage issues. FI and SWSI are based on the human water requirements from socio-economic perspectives without considering water quality [6]. WPI is a comprehensive socioeconomic indicator and consists of five major components (resources, access, capacity, use, and environment), each with several sub-components. Water quality is considered in the environment component, which includes:

- An index of water quality;

- An index of water stress;

- An index of regulation and management capacity;

- An index of information capacity;

- An index of biodiversity.

All these sub-components consist of several sub-sub-components, and some of them are qualitative variables [7]. WPI is not often used due to the complex assessment procedures and data requirement. It started to consider water quality, but it is difficult to identify the impact of water quality in this highly integrated indicator, and thus can hardly provide indicating results of improving water use.

Various studies are then performed to seek a more systematic assessment of water use [8]. One of the well-used indicators of water use assessment is the Water Footprint (WF) [9] initiated in the virtual water trade report in 2002, in which the WF assessment concept was introduced. The WF framework and calculation methods were further developed in the Water Footprint Assessment Manual [10], aiming to set a global standard. In this framework, water footprints are defined with regard to water sources, e.g., blue water footprint, green water footprint, and Grey Water Footprint (GWF), which represents the water consumption of fresh surface or groundwater, precipitation, and the volume of freshwater that is required to assimilate the load of pollutants based on natural background concentrations and existing ambient water quality standards [10]. The Water Footprint Assessment (WFA) method has been widely used and developed for water consumption analysis with various implementations. Most studies on product WF are contributed by Hoekstra and his research team [11]. Pellegrini et al. [12] investigated the green, blue, and GWF of different olive growing systems, and considered WFA as a useful tool for orchard system decision making. Deng et al. [13] studied the WF changes of China in 2002 and 2007 with an input-output model and analysed virtual water trade patterns of China. WF approaches require a robust database and concentrate mainly on the volumetric measurement of product/regional water use [14], and the measurement regarding green water was claimed incapable of revealing irrigation water use for food production [15]. Applying to wider aspects (e.g. environmental impacts) of water-related assessment, the concept and calculation methods of WF have been further developed. Blue water availability footprint, which is estimated by reducing total natural runoff by $80 \%$ to account for presumed environmental flow requirements [16], started to consider natural water availability. Ridoutt et al. [17] addressed the combination of WF with Life Cycle Assessment (LCA) framework and later developed a method [18] for WF 
calculation, emphasising the environmental impacts of water use. Following this direction, the International Organisation for Standardisation (ISO) formed an international standard - ISO 14046 - for WF evaluation [19], and a comprehensive framework was built to evaluate all water-related environmental impacts. This framework aims to perform a comprehensive WFA and includes Water Availability Footprint (WAF) and water footprints addressing water degradation [17].

Several other indicators on water quality classification are also developed to address the water degradation problems. Parparov et al. [20] developed a Water Quality Index (WQI) that takes the specific characteristics and uses of a given water resource into consideration and applied this method to water quality assessment of Lake Kinneret and Naroch Lake in Belarus. Huang et al. [21] developed a water quality classification method based on a multi-classification Support Vector Machine (SVM), and the results showed this method is more concise when classification features are unclear. The WQI [22] developed by the Canadian Council of Ministers of the Environment (CCME) [23] and National Sanitation Foundation (NSF) [24] have also been well used in water quality quantification studies [25]. Hanslík et al. [26] investigated the influence of water flowrates on the water quality in natural water bodies and found that nitrates, suspended solids and dissolved oxygen are highly influenced.

The changes of water quality should be considered because it is becoming more important under a situation of water shortage. However, water quality and the environmental impact of water use has been less addressed in WFA framework, even though it is an important factor for water use [27]. The concept of GWF started to consider the environmental impact of water pollutants, while the condition and changes of water quality during water use processes were rarely considered both in theoretical frameworks and in practical assessments. The ISO WF approach starts to consider water quality as an impact factor of water availability and noted that water quality should be considered, but the involvement of water quality in WFA in practical implementations has not been well interpreted yet.

At present, most classification methods have been developed based on a single water quality metric [e.g., Chemical Oxygen Demand (COD), Biologocal Oxygen Demand (BOD)] and then are applied to the single body of surface water. Most water quality indicators concern more on specific surface water bodies in terms of chemical or biological indicators, and the water quality indicators are rarely considered for a macro water use assessment. There has been still a need to extend the single water quality indices to multiple metrics to provide a more complete picture of its usability.

This study aims to further develop WF assessment framework that incorporates multiple water quality indices to qualify and usability of surface water bodies. To achieve this goal, this paper first investigates the developments of the current WF assessment methods and redefines the water availability regarding water quality. Based on this definition, a WAF assessment framework is proposed. A case study is carried out to illustrate the procedures of applying the framework. The potential and strength of this framework as well as the suggestions for future studies are discussed.

\section{COMPARATIVE ANALYSIS OF WATER FOOTPRINT APPROACHES}

The concept of water footprint has been widely used to quantify water consumption. This sections overview and analysed the approaches used for water consumption footprinting, and try to link the water consumption, water quality degradation, to the issue of water availability decrease.

\section{Conventional water footprints}

Water footprint, introduced by Hoekstra and Hung [9], has been widely used for the quantification of the human water consumption. As the water degradation issues are 
rising, the WF assessment is starting to consider the anthropogenic impact on water quality. A comparison of various water footprints regarding water quality is presented in Table 1.

In the WF framework developed by Hoekstra et al. [9], GWF is used to quantify the environmental impact of water pollutants. But it can only determine one pollutant as the indicator for water quality, which can be limited to reveal the bigger picture. For instance, when investigating the grey footprint of a plant, from which the effluents usually contain many kinds of contaminants. The selection of the assessed pollutant would greatly affect the result of the GWF which makes the comparison between different water use systems more difficult. The WF addressing water degradation introduced in ISO 14046 [19] tries to assess the comprehensive environmental impact on water quality by assessing various impact categories. Assessment methods are developed according to the framework in the standard [28], but no unified and generally accepted method has been developed and implemented so far. One critical issue of this framework is that the characteristic factor is difficult to determine. Since the Water Degradation Footprint (WDF) is calculated by multiplying the mass of the pollutant to the characteristic factors, the update of the factors affects the accuracy of the water degradation footprint.

Table 1. Comparison of water footprints regarding water quality

\begin{tabular}{|c|c|c|}
\hline & GWF [29] & WDF [19] \\
\hline Definition & $\begin{array}{c}\text { The volume of water required to } \\
\text { assimilate pollutants entering freshwater } \\
\text { bodies }\end{array}$ & $\begin{array}{c}\text { The potential environmental impacts related } \\
\text { to water quality, regarding different impact } \\
\text { categories }\end{array}$ \\
\hline $\begin{array}{l}\text { Assessment } \\
\text { framework }\end{array}$ & $\begin{array}{c}\mathrm{WF}_{\mathrm{grey}}=\frac{C_{\mathrm{effl}}-C_{\mathrm{act}}}{C_{\mathrm{max}}-C_{\mathrm{nat}}} \times E_{\mathrm{ffl}} \\
\text { where } C_{\mathrm{effl}}, C_{\mathrm{act}}, C_{\mathrm{max}} \text {, and } C_{\mathrm{nat}} \text { are the } \\
\text { concentrations of the pollutant in the } \\
\text { effluent, the intake water, the maximum } \\
\text { acceptable and natural concentration of } \\
\text { the water bodies, } E_{\mathrm{ffl}} \text { is the effluent } \\
\text { volume }\end{array}$ & $\begin{array}{l}\qquad \mathrm{WDF}=\sum_{i}\left(M_{i} \times I f_{i}\right) \\
\text { where } M_{i} \text { is the mass of the pollutant i, If } f_{i} \text { is } \\
\text { the characteristic factor of the pollutant, } \\
\text { which is determined according to different } \\
\text { impact categories on human or the ecosystem, } \\
\text { e.g. acidification, eutrophication, } \\
\text { eco-toxicity, etc. }\end{array}$ \\
\hline $\begin{array}{l}\text { Water quality } \\
\text { and purpose } \\
\text { of water use }\end{array}$ & $\begin{array}{l}\text { GWF selects } 1 \text { critical pollutants for the } \\
\text { whole assessing system, quality of input } \\
\text { water was not considered, purpose of } \\
\text { water use not considered }\end{array}$ & $\begin{array}{l}\text { More impact categories, while only the } \\
\text { mathematical summation of the pollutants, the } \\
\text { impact indicators are difficult to measure, not } \\
\text { as one indicator and difficult to compare, } \\
\text { purpose of water use not considered }\end{array}$ \\
\hline $\begin{array}{l}\text { Tracing of } \\
\text { water quality } \\
\text { changes }\end{array}$ & $\begin{array}{l}\text { Not considered, can only assess one kind } \\
\text { of pollutant, expressed in } \mathrm{m}^{3} \text { water needed } \\
\text { to dilute the polluted water to the required } \\
\text { level }\end{array}$ & $\begin{array}{l}\text { Not considered, treat water discharge into the } \\
\text { environment as elementary flows of the WF } \\
\text { inventory, the water availability of water } \\
\text { discharge was not considered }\end{array}$ \\
\hline
\end{tabular}

It is obvious that there is an urgent need for the development of the methodology for comprehensive assessment of human exploitation of water quantity and water quality. Integrating water quality and quantity, the method should also consider the water quality changes during the water use process, which is the "footprint" of water use.

\section{Water availability and footprint}

Various definitions of water availability have been offered, and it has been defined mainly as the amount of fresh water that is available for human activities. Alcamo et al. [30] defined water availability as the total river discharge, which combined the surface runoff and groundwater recharge. In their study, water availability is used interchangeably with "discharge" and "annual renewable water resources" within a river 
basin. Hoekstra et al. [29] defined the blue water availability as the volume of water that can be consumed without expected adverse ecological impacts. In most situations, water availability was considered as the amount of water that can be used by human activities after subtracting the ecosystem internal self-maintaining demands. Döll et al. [31] estimated the water availability by calculating the annual renewable discharge that is available and assumed that the amount of water that can be used for each month of the year is equal to the Q90-value. Hoekstra [29] calculated the blue water availability by reducing total natural runoff by $80 \%$ to account for presumed environmental flow requirements. For monthly water availability, it is calculated as the "natural runoff" in the basin minus "environmental flow requirement" [29].

The ISO WF framework starts to consider the importance of water quality on water availability. Water availability is defined as the extent to which humans and ecosystems have sufficient water resources for their needs [19], and WAF is defined as the contribution of water use processes to potential environmental impacts related to stress on water availability. It considers water quality as an essential element of WAF [19], while only a few WAF assessment studies were conducted based on this standard. Huang et al. [32] use an LCA based-water footprint method to assess the WAF of milk and milk products, but they only assess consumptive water use in the context of water shortage. Water quality was noticed with its influence on water availability, while it has rarely been analysed in practical water resource assessments. One possible reason is that water quality is a complex indicator, and water quality classification research has not yet resulted in a clear indicator that is easy to use in water availability assessment.

Since the water footprinting concept and method has been well developed with various implementations, integrating water quality into the current assessment framework further contribute to the quantification of water availability. Based on the current framework, the definition of water availability should be extended to consider the impact of water quality on water availability, and the determination of WAF should be adapted to reach an integrating result. In addition, water availability should also consider the purpose of water use, since it is possible that the same body of water has different usability for various purposes, e.g., drinking or producing a piece of cloth. It becomes inappropriate to claim that for two different processes, consuming the same amount of water means the same WAF. Based on the WAF defined by ISO [19], the present paper extends the definition of WAF integrating water quality and quantity and proposes a brief framework to illustrate its application.

\section{WATER AVAILABILITY FOOTPRINT ASSESSMENT FRAMEWORK}

Identifying the amount of water that is available from a given source is the first step for water use assessment, and it is necessary to quantify the quality of this water supply. A clear definition and application framework are remarkably needed. Aiming to assess the quality-quantity consumption of water use, a WAF should focus on the following aspects:

- Integrating water quality and water quantity. Water use process may change the quantity or quality, or both simultaneously. Water availability changes in any of these scenarios. The integrated consideration implies that for the same amount of available water volume, the water stream with higher quality provides larger availability;

- Reflecting the purpose of water use. Water use sectors, such as industry, household (washing and drinking), and agriculture, usually have different emphasis on water quality features. For most industrial water use, the requirement is more related to general physical and chemical properties, such as the concentration of Suspended Solids (SS), minerals, COD, BOD, etc. For 
household water use, the water quality requirement is often higher regarding water cleaning and safety. For irrigation, it may require water with lower (heavy metal) toxicity and alkalinity. Considering these demands, a certain water supply may have different availability for different purposes of water use. If a water supply is used for a purpose with higher quality requirements, it may need other resources (energy or supplementary cleaner water) to improve the water quality and the usability [33];

- Considering the availability of water discharge. Wastewater discharged from a water use process or treatment plant may be used directly for processes with a lower quality requirement or discharged into river water after proper treatment. In both situation the water becomes "newly" available and can be used for other users. Therefore, the availability of this part of water should be counted.

Combining the above-mentioned key points, water availability is defined as follows: the quantitative and qualitative extent of a certain body of water which meets the needs of a certain purpose of water use. Comparing this definition to the conventional water availability, the water availability proposed in this study integrates water quality and quantity and can be defined as the Effective Water Availability (EWA). Based on this definition, WAF can be defined as the water availability consumption of a certain water use process. Following these definitions, a brief framework is built to demonstrate the assessment procedures of WAF, and a case study is carried out to illustrate the application.

\section{Assessment framework}

The WAF assessment of a unit process mainly contains three steps (Figure 1).

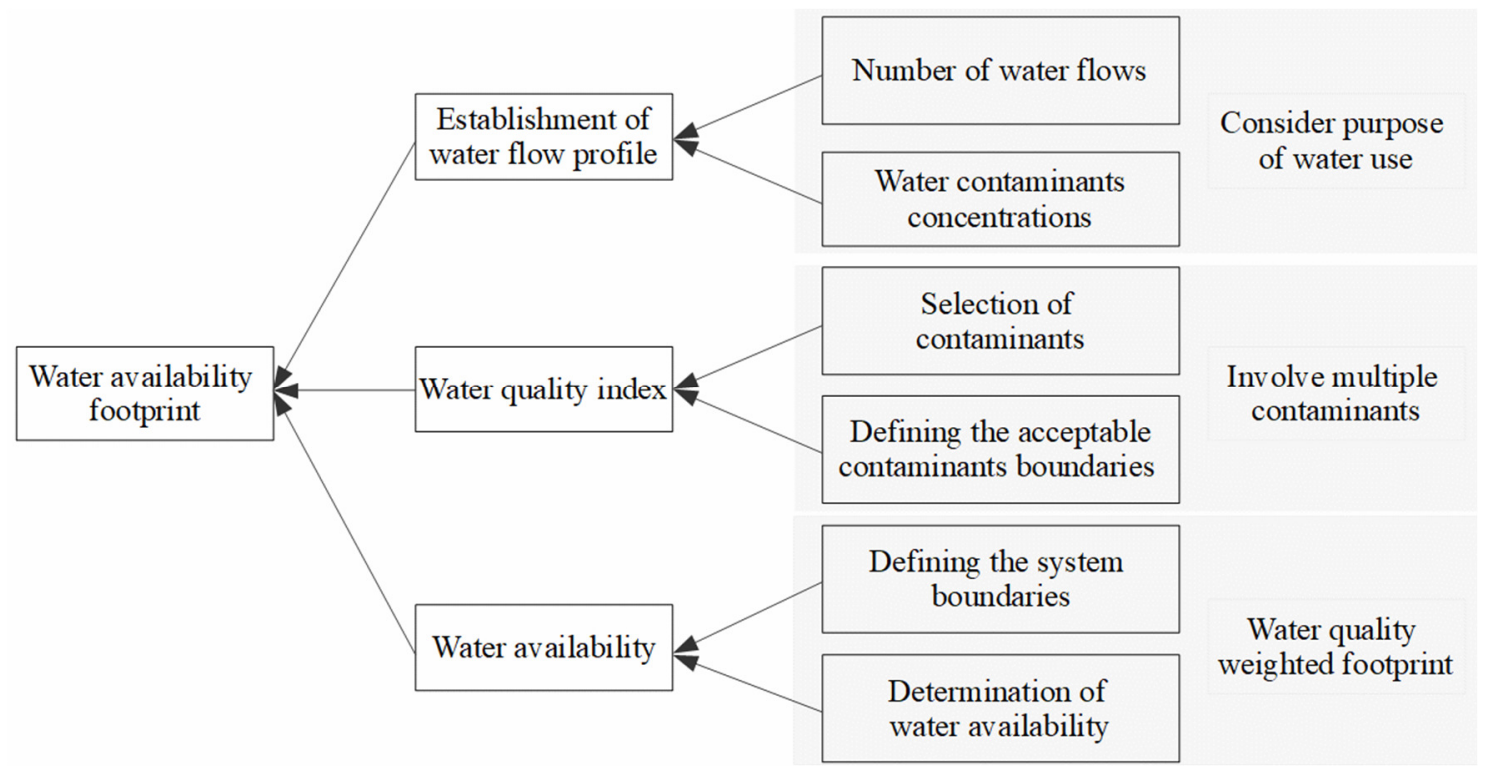

Figure 1. WAF assessment framework

The first step is to develop the water flow profile, define the system boundary and list all the flows that get in/out of the system. Water quality is not an absolute value, but an indicator consisting of various physical and chemical indices. Quantifying and integrating water quality into WAF becomes the most difficult step. Based on the water flow profile and water quality index, the EWA can be assessed.

Considering that it is hardly possible to compare the absolute value of all tested physical/chemical indices, this study recommends a WQI, which is a relative value, to make it more objective and comparable. Inspired by the Water Stress Index (WSI) [34], 
which is a ratio of water consumption (demand) and water availability (supply), this study proposes a ratio of water quality demands and water quality supplies as the WQI.

\section{Water Quality Index}

Following this consideration, the definition of the WQI proposed in this study is given: For a certain flow (body of water), WQI is the ratio between remaining allowance of pollutant discharge and the maximum acceptable pollutant allowance, which can be calculated as in eq. (1). It is based on the purpose of water use and the specific situation of the targeted region/area. The idea of WQI is to scale all the inflow and outflow of the system to be comparable. By defining the upper and lower bounds of the contaminants, the range of allowed concentrations in certain water bodies is given. Knowing the water profiles of the flows, the "credit" of each water flow in this region can be calculated, as a representation of water quality:

$$
\mathrm{WQI}_{i}=\frac{X_{\max , i}-X_{i}}{X_{\max , i}-X_{\min , i}}
$$

where for pollutant $i, \mathrm{WQI}_{i}$ is the water quality index of a certain water flow, $X_{i}$ is the concentration of pollutant $i, X_{\max , i}$ is the upper bound of acceptable the concentration of this pollutant, and $X_{\min , i}$ is the lower bound of the acceptable concentration of pollutant $i$. The upper and lower bounds of the concentration of pollutants can be selected from national/regional water quality standards or defined according to the current water quality levels in the studied region.

This study is trying to propose an index to integrate water quality with water quantity, even though at this stage, it is still difficult to cover all aspects of the water flow profile and solve the issues of multiple contaminants. Considering the complexity of the water quality assessment, the following assumptions are made to firstly simplify the calculation:

- The number of contaminants $(i)$ can be changed according to the availability and quality of data;

- $X_{i}$ can be smaller than $X_{\min , i}$, which is the lower bound of the accepted concentration of contaminant $i$. When the value of $X_{\min , i}$ is selected from local standard, it is possible that the values of the standard are still lower than some water bodies because the standard value can be at an average level;

- When $X_{i}$ is larger than $X_{\max , i}$, then $\mathrm{WQI}_{i}=0$.

When $i$ kinds of contaminants are considered, there would be multiple values of WQI for one water flow. Reaching a single value of WQI is necessary to quantify the EWA. In this study, two possible approaches are explored to quantify the overall water quality. One approach is to consider the most stringent pollutant as the bottleneck of water utilisation [eq. (2)], which can be useful for water use with higher water quality requirement. For example, if the concentration of Lead $(\mathrm{Pb})$ in a water flow exceeds the requirement for drinking water, then the WQI of this water flow for drinking water is 0 . Consequently, the EWA of this drinking water body for drinking would be 0 :

$$
\mathrm{WQI}_{\min }=\min \left(\mathrm{WQI}_{1}, \mathrm{WQI}_{2}, \ldots, \mathrm{WQI}_{i}\right)
$$

where $\mathrm{WQI}_{\min }$ is the water quality index of the water flow and $\mathrm{WQI}_{i}$ is the WQI of contaminant $i$.

Another option is to calculate the average of the WQI's of all contaminants as the WQI of the flow (WQI $\mathrm{I}_{\mathrm{avg}}$ ), as shown in eq. (3). In this case, it is assumed the water quality is determined by all the contaminants, which are affecting the water stream independently of each other, and the concentrations of the contaminants are much lower 
than their saturation levels. The average WQI can reflect the overall distribution of the pollutant concentrations and can be used for the situation that does not have strict water quality requirement, e.g. industrial cooling water, etc.:

$$
\mathrm{WQI}_{\mathrm{avg}}=\frac{1}{n} \sum_{i=1}^{n} \mathrm{WQI}_{i}
$$

where $\mathrm{WQI}_{\mathrm{avg}}$ is the WQI of the water flow and is calculated with the average of the WQI of all the contaminants. The applications of these two options are discussed in the case study in the following sections.

\section{Water Availability Footprint calculation}

For various purposes of water use, both water quantity and quality affect the extent of the availability of the water supply. Considering the correlation between water quality and water quantity, as well as their impact on the water usability, WQI can be considered as a weighting factor of water quantity, and the EWA can be calculated by eq. (4):

$$
\mathrm{EWA}=A_{\mathrm{W}} \times \mathrm{WQI}
$$

where EWA is the effective water availability of a water body $\left[\mathrm{m}^{3}\right], A_{\mathrm{W}}$ is the amount of water (input or output) $\left[\mathrm{m}^{3}\right]$, and WQI is the water quality index, which is a dimensionless quantity.

As water availability is defined as the changes of water availability during the water use process, for each water use unit process, the WAF can be calculated as the difference between all inputs and outputs of a certain process, as shown in eq. (5):

$$
\mathrm{WAF}=\mathrm{EWA}_{i}-\mathrm{EWA}_{\mathrm{o}}
$$

where WAF is the water availability footprint of the water use process $\left[\mathrm{m}^{3}\right], \mathrm{EWA}_{i}$ is the effective water availability of the input water flow $\left[\mathrm{m}^{3}\right]$, and $\mathrm{EWA}_{\mathrm{o}}$ is the effective water availability of the output water flow $\left[\mathrm{m}^{3}\right]$.

The WAF is calculated to reflect the usability changes before and after the water use process. The estimation of WQI is more difficult for the determination of water availability. Dealing with the multi-contaminants issues, the selection of the pollutants should be based on the practical situation of the assessing region, and the purpose of water use should be considered to determine the upper and lower bound of the pollutant. The following case study shows the potential implementation of the WAF assessment framework.

The water quality should be accounted for jointly with the water availability because this can provide the additional insights for water managers into improving water quality and water availability of the systems. In the provided case study, this is illustrated with a Radar chart.

\section{CASE STUDY}

In order to illustrate the application of the proposed framework, a numerical case study is carried out in this section. Let us assume an industrial water use process attached to a primary water treatment unit located in China. The system boundary is shown in Figure 2. The input flow is from a water supply with certain volume and quality $\left(\mathrm{F}_{1}\right.$, $\left.\mathrm{WQI}_{1}\right)$, and outflow $\left(\mathrm{F}_{2}, \mathrm{WQI}_{2}\right)$ is discharged into the same water supply system. Within the water use system, some flows might be reused directly $\left(\mathrm{F}_{3}\right)$ or recycled $\left(\mathrm{F}_{4}\right)$ or exist 
between the treatment unit $\left(\mathrm{F}_{5}\right)$. Considering $\mathrm{F}_{5}$ does not have direct effect on the outside system, they are not considered during the WAF assessment.

In this case study, it is important to define the upper and lower bounds of the pollutants to calculate the $\mathrm{WQI}_{i}$. The inflow $\left(\mathrm{F}_{1}=2,000 \mathrm{~m}^{3}\right)$ should meet the requirement of the water use process, and the discharge flow $\left(F_{2}=1,000 \mathrm{~m}^{3}\right)$ entering the natural water bodies should meet the water discharge standards. The maximum and minimum acceptable concentration of pollutants is set according to the water discharge standard.

The water use requirements are referred from the Environmental Quality Standards for Surface Water (GB3838-2002) [35]. In this standard, the surface water in China is divided into five categories regarding the purpose of water use, and a range of the concentrations of selected contaminants is given for each category. Category I is the water with the best quality and is supposed to be used for water sources for national natural reservation areas. Category II and III can be used as sources of domestic water use, and the aquatic environment for fishes, etc. The water of Category IV is for industrial water use and entertainment water use (indirectly exposed to human bodies). As the case study is for industrial water use process, Category IV is considered as the maximum allowed concentrations of the contaminants $\left(X_{\max , i}\right)$.

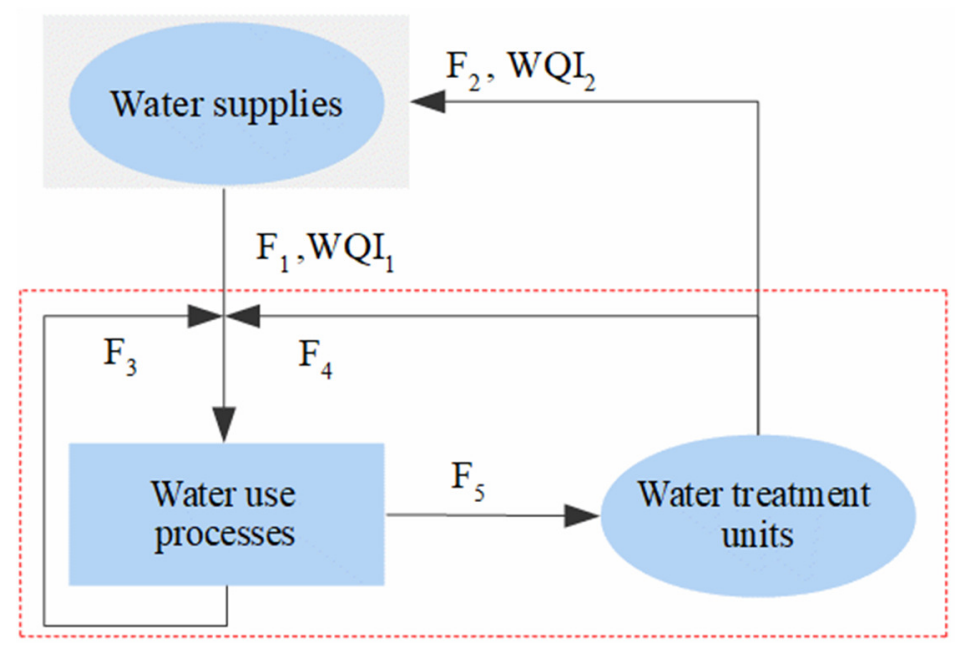

Figure 2. Case study: WAF framework and system boundaries

The water discharge requirements are taken from the Discharge Standard of Pollutants for Municipal Wastewater Treatment Plant (GB 18918-2002) [36]. It is required that the discharge water from the water treatment plant should meet the Category B and the criteria of this category are set as the minimum allowed concentrations $\left(X_{\min , i}\right)$.

In order to make the inflow and outflow comparable, they are scaled with the same ranges, which means $X_{\min , i}$ and $X_{\max , i}$ are the same for the two flows. Aiming to identify the impact of different water quality on the WAF, we set 3 different water quality profiles for $\mathrm{F}_{2}$, which are $\mathrm{F}_{2-1}, \mathrm{~F}_{2-2}$ and $\mathrm{F}_{2-3} . X_{\max , i}$ and $X_{\min , i}$ as well as the contaminant concentration of flows are shown in Table 2.

With eq. (1) and the water quality data provided in Table 2, the WQI is calculated (Figure 3). The green bar is the WQI for $F_{1}$, which is the inflow. $F_{2-1}, F_{2-2}$, and $F_{2-3}$ are the different flows with a different water quality pattern to test the impact of water quality on WAF. $F_{2-1}$ is the water flow with relatively higher overall water quality, but the levels of different contaminants are not distributed evenly. $F_{2-2}$ is a water flow with lower overall quality, and the levels of the contaminants are quite even. $F_{2-3}$ is a water flow with medium overall water quality, and the levels of the contaminants are also distributed evenly. 
Table 2. Water quality criteria of boundaries and flows in the system

\begin{tabular}{|c|c|c|c|c|c|c|}
\hline$X_{i}\left[\mathrm{mg} / \mathrm{m}^{3}\right]$ & $X_{\max , i}$ & $X_{\min , i}$ & $F_{1}$ & $F_{2-1}$ & $\mathrm{~F}_{2-2}$ & $F_{2-3}$ \\
\hline Chemical Oxygen Demand (COD) & 100 & 20 & 25 & 38 & 80 & 60 \\
\hline $\begin{array}{l}\text { 5-day Biochemical Oxygen } \\
\text { Demand }\left(\mathrm{BOD}_{5}\right)\end{array}$ & 30 & 4.0 & 5.0 & 8.0 & 26 & 17 \\
\hline Ammonia Nitrogen $\left(\mathrm{NH}_{3}-\mathrm{N}\right)$ & 20 & 1.0 & 1.2 & 1.8 & 15 & 10 \\
\hline Total Phosphorous (TP) & 3.0 & 0.2 & 0.22 & 0.35 & 2.6 & 1.6 \\
\hline Zinc (Zn) & 20 & 1.0 & 1.2 & 1.6 & 14 & 10 \\
\hline Fluoride ion $\left(\mathrm{F}^{-}\right)$ & 1.5 & 1.0 & 1.0 & 1.4 & 1.3 & 1.2 \\
\hline Arsenic (As) & 0.1 & 0.05 & 0.06 & 0.09 & 0.08 & 0.07 \\
\hline Mercury $(\mathrm{Hg})$ & 0.001 & 0.0001 & 0.0002 & 0.001 & 0.0007 & 0.0005 \\
\hline Chromium (Cd) & 0.1 & 0.005 & 0.005 & 0.007 & 0.07 & 0.052 \\
\hline Lead $(\mathrm{Pb})$ & 0.1 & 0.05 & 0.042 & 0.06 & 0.08 & 0.07 \\
\hline
\end{tabular}

Note: $X_{\max , i}$ and $X_{\min , i}$ are referred from SEPAC, 2002

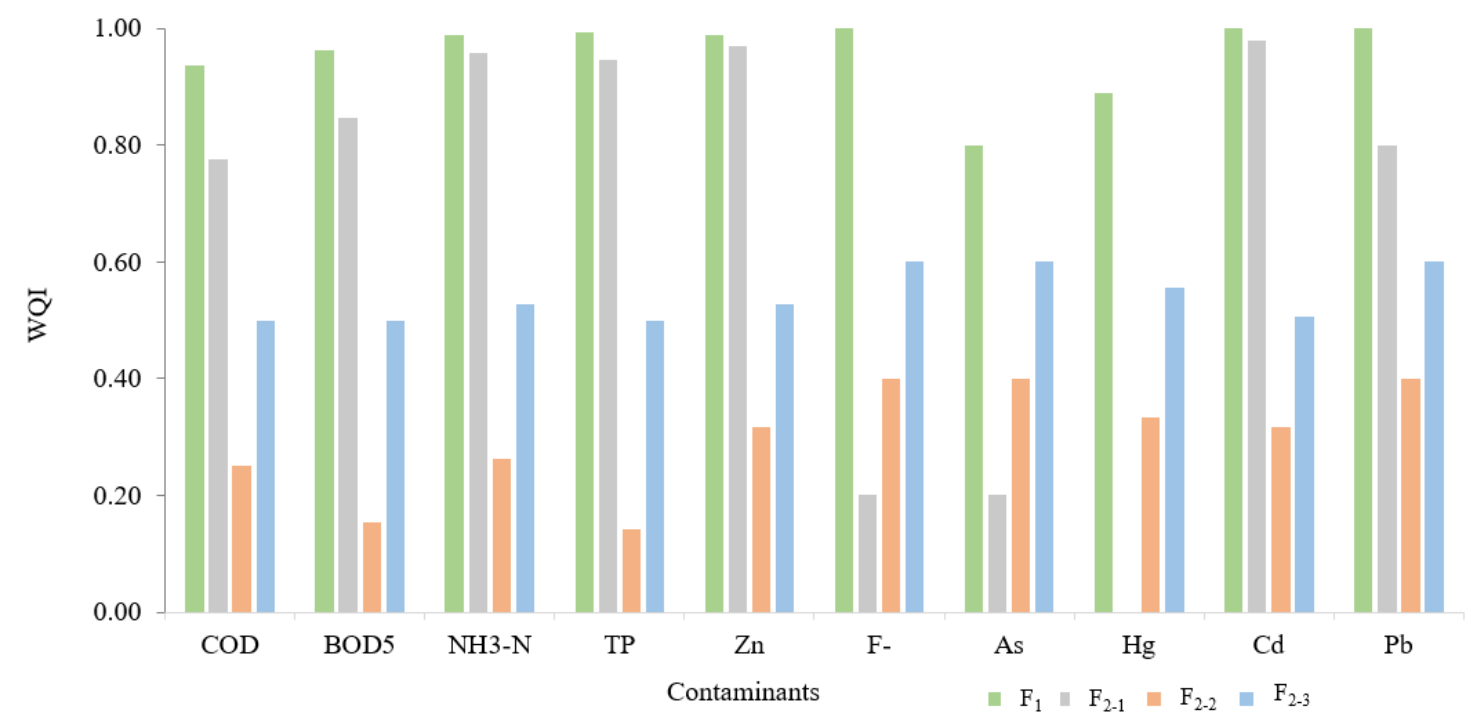

Figure 3. WQI of 10 selected contaminants

To consider the two options for determining the overall WQI mentioned in the methodology section, the overall WQI based on $\mathrm{WQI}_{\mathrm{min}, i}$ and $\mathrm{WQI}_{\mathrm{avg}, i}$ are calculated. The EWA of the inflow $\left(\mathrm{F}_{1}\right)$ and outflow under 3 different situations $\left(\mathrm{F}_{2-1}, \mathrm{~F}_{2-2}\right.$, and $\left.\mathrm{F}_{2-3}\right)$ are determined. The WAF can be calculated by $\mathrm{EWA}_{i}$ minus the $\mathrm{EWA}_{\mathrm{o}}$. The EWA of all the flows and the and WAF of the system are shown in Table 3.

Table 3. Overall WQI and EWA of the flows and the WAF of the system

\begin{tabular}{ccccc}
\hline Indicators & $\mathrm{F}_{1}$ & $\mathrm{~F}_{2-1}$ & $\mathrm{~F}_{2-2}$ & $\mathrm{~F}_{2-3}$ \\
\hline${\text { Volume }\left[\mathrm{m}^{3}\right]}_{\mathrm{WQI}_{\min }}^{2,000}$ & 1,000 & 1,000 & 1,000 \\
$\mathrm{WQI}_{\text {avg }}$ & 0.80 & 0.00 & 0.14 & 0.50 \\
$\mathrm{EWA}_{i}\left[\mathrm{~m}^{3}\right]$ based on WQI & 0.97 & 0.67 & 0.30 & 0.54 \\
$\mathrm{WAF}_{\text {min }}\left[\mathrm{m}^{3}\right]$ & 1,600 & 0.00 & 142.86 & 500 \\
$\mathrm{EWA}_{\mathrm{o}}\left[\mathrm{m}^{3}\right]$ based on WQI & & 1,600 & 1,457 & 1,100 \\
$\mathrm{WAF}_{\text {avg }}\left[\mathrm{m}^{3}\right]$ & 1,944 & 667 & 297 & 541 \\
Volumetric WAF $\left[\mathrm{m}^{3}\right]$ & & 1,277 & 1,646 & 1,402 \\
& & & 1,000 & \\
\hline
\end{tabular}

The WAF of the water use process can be calculated as:

- With $\mathrm{WQI}_{\mathrm{min}, i}$, the WAF is: $\mathrm{WAF}=\mathrm{EWA}_{1}-\mathrm{EWA}_{2}=1,600 \mathrm{~m}^{3}$;

- With $\mathrm{WQI}_{\mathrm{avg}, i}$, the WAF is: $\mathrm{WAF}=\mathrm{EWA}_{1}-\mathrm{EWA}_{2}=1,291 \mathrm{~m}^{3}$. 
While if only water quantity is considered, the water consumption during this process is $F_{1}-F_{3}=1,000 \mathrm{~m}^{3}$.

$\mathrm{F}_{1}$, as the water supply, has the best water profile, with higher $\mathrm{WQI}_{\min }$ and $\mathrm{WQI}_{\mathrm{avg}}$, and therefore has the largest EWA. The WAF's calculated in all situations are higher than the volumetric WF $\left(1,000 \mathrm{~m}^{3}\right)$, which indicates that considering water quality in WF assessment can yield a more stringent result. The water usability decrease during the water use process is determined more effectively. Only considering amount of water consumption one can neglect the impact of water quality changes.

For the results of $\mathrm{WAF}_{\min }$, it showed that water bodies with more evenly distributed WQI's have the smaller footprint and thus have higher EWA. For the results $\mathrm{WAF}_{\text {avg, }}$, as the average values revealed, the higher overall WQI, the smaller footprints. For $F_{2-1}$, the EWA based on WQI $\mathrm{I}_{\min }$ becomes 0 and independent on the volume of discharge. It indicates that the minimum WQI approach is not applicable for industrial water use but can be applicable for more strict water uses, such as drinking water. On the other hand, the averaged WQI can continuously represent the water availability changes. In addition, the averaging determination compromises the impact of all the contaminants, which indicates that this approach is more suitable for the assessment of water flows with moderate quality profiles. Applying weighting factors to different contaminants is one of the possible ways to improve the application of the average WQI. The radar chart was used to find out the critical contaminant of the flow, as is shown in Figure 4.

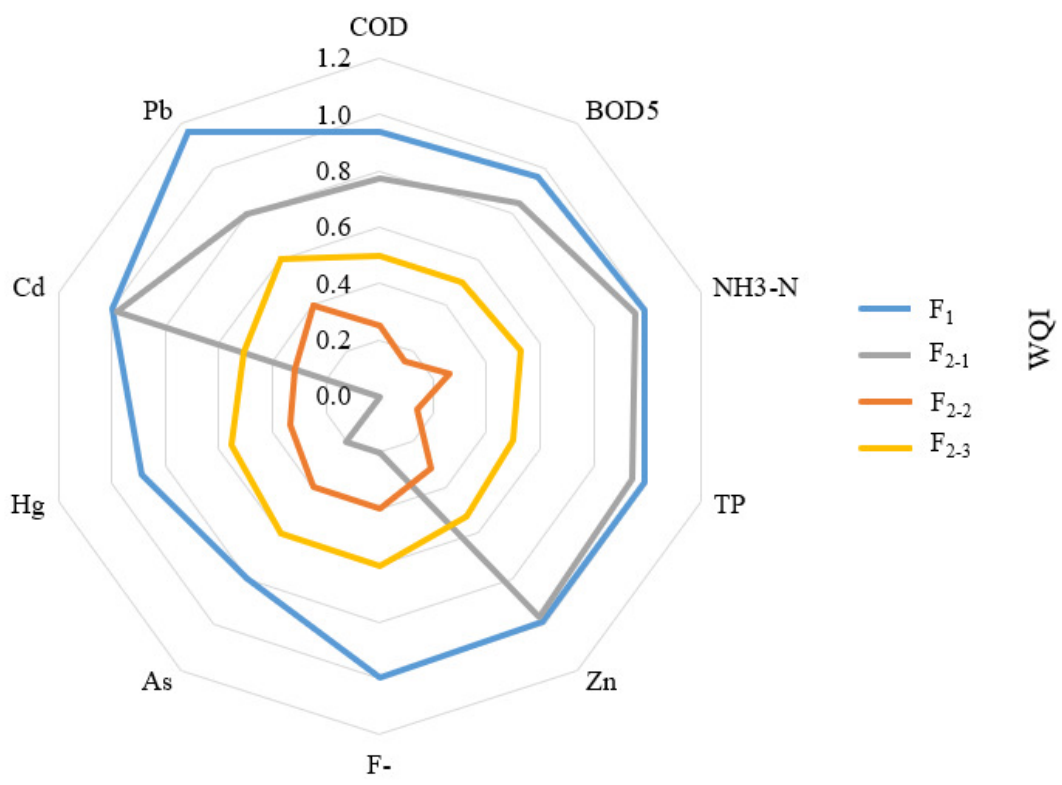

Figure 4. Radar chart of WQI of the flows from case studies

The radar chart is able to illustrate the distribution of WQI's of all contaminants, and it also shows the bottleneck of the flow. For example, in Figure 4, the pollutants in $F_{1}$ are more uniformly distributed, and water quality is more moderate. While for $F_{2-1}$, it is obvious that the $\mathrm{Hg}$ is the most constraining pollutant (WQI $=0$ ), followed by As and $\mathrm{F}^{-}$ (WQI $=0.20$ ). This can provide useful information for the water users or managers to detect the bottleneck and improve the water flow accordingly to improve water use efficiency.

\section{DISCUSSION}

The WAF framework proposed in this paper tries to involve water quality into the WF assessment framework that is widely used. The involvement of water quality describes the usability change of the water flow beyond water quantity, in order to provide more 
solution-oriented results. Defining water availability from the demand side and taking water quality into consideration, can contribute to a more specific measurement for WF assessment, and provide more support for improving the allocation to become closer to the optimal water and wastewater resources.

The framework still has some limitations needs to be considered in the future works:

- A WQI that can be applied to more general situations has not been suggested in this study. The two approaches considered are limited to certain situations. The minimum WQI can be used for water flows that require higher water quality, and the average WQI can be used for flows that have more moderate quality;

- The different environmental impacts of all contaminants and the interactions among contaminants are not considered;

- Only one kind of water use is considered. When applying to a larger scale (e.g., region or country), with more than one kind of water use categories (e.g., industrial, agricultural, municipal, etc.), the baselines of the multiple contaminants would depend on the purpose of water use. With the results calculated with different baselines, it needs further discussion whether they can be added directly.

These limitations, especially the WQI of multi-contaminants are the most critical part of the framework, which should be further investigated in future works.

\section{CONCLUSIONS}

The attempt to optimise industrial processes and other resource-consuming activities has attracted a lot of research efforts. As reviewed recently by Fan et al. [37], many new developments have been presented, focusing on energy and materials efficiency improvements. Following this trend, the current paper proposed an extended approach to WAF to quantify water availability. Based on the analysis of WF assessment methods, water quality is integrated into the assessment. EWA has been defined as the quantitative and qualitative extent of a certain body of water which meets the needs of a certain purpose of water use, and a WAF is proposed to determine the human water exploitation of water availability of water quality and quantity. A WQI is proposed to quantify the contribution of water quality on EWA.

The extension to water footprinting approaches has been developed and implemented with a case study. 3 outflows are set to discuss the impact of different water quality pattern on the result of WAF. The results showed that for the WAF calculated based on minimum WQI, systems with more average outflows have the lower WAF. The distribution of pollution levels also affects water availability besides the actual pollutant concentration. For the WAF calculated based on average WQI, it indicated that the overall WQI is the only factor for WAF. The case study shows that for the industrial process considered, the WAF calculated based on the concepts of minimum WQI, average WQI, and the blue WF is $1,600 \mathrm{~m}^{3}, 1,277 \mathrm{~m}^{3}$, and $1,000 \mathrm{~m}^{3}$ (in the case of $\mathrm{F}_{2-1}$ ). The volumetric footprint is much less than the water footprints considering water quality, which might lead to misleading suggestions. The WAF considers water quality can reveal many issues neglected by the only-volumetric calculation of blue water footprint. The radar chart of the WAF of multiple contaminants is effective to demonstrate the distribution of the pollutants, which can provide more specific information for water users or managers for minimising water use or improving water quality control.

The proposed method still has limitations on the comprehensive determination of multiple contaminants, which should be further investigated in future studies. The indication of water quality and effective availability are not yet robust for practical application. In addition, the impact of secondary pollutions should be considered in future developments. 


\section{ACKNOWLEDGEMENT}

The EU supported project Sustainable Process Integration Laboratory (SPIL) funded as project No. CZ.02.1.01/0.0/0.0/15_003/0000456, by Czech Republic Operational Programme Research and Development, Education, Priority 1: Strengthening capacity for quality research in the collaboration agreement with the Universiti Teknologi Malaysia (UTM) based on the SPIL project are gratefully acknowledged.

\section{REFERENCES}

1. Klemeš, J. J, Industrial Water Recycle/Reuse, Curr. Opinion in Chem. Eng., Vol. 1, No. 3, pp 238-245, 2012, https://doi.org/10.1016/j.coche.2012.03.010

2. Wan Alwi, S. R. and Manan, Z. A., Targeting multiple Water Utilities using composite Curves, Industrial \& Engineering Chemistry Research, Vol. 46, No. 18, pp 5968-5976, 2007, https://doi.org/10.1021/ie061238k

3. Falkenmark, M. and Widstrand, C., Population and Water Resources: A delicate Balance, Population Bulletin, Vol. 47, No. 3, pp 1-36, 1992.

4. Ohlsson, L., Water conflicts and Social Resource scarcity, Physics and Chemistry of the Earth Part B: Hydrology Oceans and Atmosphere, Vol. 25, No. 3, pp 213-220, 2000, https://doi.org/10.1016/S1464-1909(00)00006-X

5. Sullivan, C. A., Calculating a Water Poverty Index, World Development, Vol. 30, No. 7 , pp 1195-1210, 2002, https://doi.org/10.1016/S0305-750X(02)00035-9

6. Jia, X. X., Yan, Y., Zhu, C. Y., Bai, X., Hu, M. T. and Wu, G., Approaches for Regional Water Resources Stress assessment: A review (in Chinese), Journal of Natural Resources, Vol. 31, No. 10, pp 1783-1791.

7. Lawrence, P., Meigh, J. and Sullivan, C., The Water Poverty Index: An International comparison, Keele Economics Research Papers, 19, Keele University, Staffordshire, UK, 2002.

8. Manan, X. A. S., Tea, S. Y. and Wan-Alwi, S. R., A new Technique for simultaneous Water and Energy minimisation in Process, Chemical Engineering Research and Design, Vol. 87, No. 11, pp 1509-1519, 2009, https://doi.org/10.1016/j.cherd.2009.04.013

9. Hoekstra, A. Y. and Hung, P. Q., Virtual Water trade: A quantification of Virtual Water flows between Nations in relation to international Crop trade, Value of Water research Report Series, Vol. 11, UNESCO-IHE, Delft, The Netherlands, 2003.

10.Hoekstra, A. Y., Chapagain, A. K., Aldaya, M. M. and Mekonnen, M. M., The Water Footprint Assessment Manual, Earthscan, London, UK, 2011.

11.Zhang, Y., Huang, K., Yu, Y. and Yang, B., Mapping of Water Footprint research: A Bibliometric analysis during 2006-2015, Journal of Cleaner Production, Vol. 149, pp 70-79, 2017, https://doi.org/10.1016/j.jclepro.2017.02.067

12.Pellegrini, G., Ingrao, C., Camposeo, S., Tricase, C., Contò, F. and Huisingh, D., Application of Water Footprint to Olive growing Systems in the Apulia Region: A comparative assessment, Journal of Cleaner Production, Vol. 112, Part 4, pp 2407-2418, 2016, https://doi.org/10.1016/j.jclepro.2015.10.088

13.Deng, G., Ma, Y. and Li, X., Regional Water Footprint evaluation and Trend analysis of China-based on Interregional Input-output Model, Journal of Cleaner Production, Vol. 112, Part 5, pp 4674-4682, 2016, https://doi.org/10.1016/j.jclepro.2015.07.129

14.Pfister, S., Boulay, A. M., Berger, M., Hadjikakou, M., Motoshita, M., Hess, T., Ridoutt, B., Weinzettel, J., Scherer, L., Döll, P. and Manzardo, A., Understanding the LCA and ISO Water Footprint: A response to Hoekstra (2016) "A Critique on the Water-scarcity weighted Water Footprint in LCA", Ecological Indicators, Vol. 72, pp 352-359, 2017, https://doi.org/10.1016/j.ecolind.2016.07.051 
15.Fereres, E., Villalobos, F. J., Orgaz, F., Minguez, M. I., Van Halsema, G. and Perry, C. J., Commentary: On the Water Footprint as an Indicator of Water use in Food production, Irrig. Sci., Vol. 35, No. 2, pp 83-85, 2017, https://doi.org/10.1007/s00271-017-0535-y

16.Hoekstra, A. Y., Mekonnen, M. M., Chapagain, A. K., Mathews, R. E. and Richter, B. D., Global monthly Water scarcity: Blue Water Footprints versus Blue Water availability, PLoS ONE, Vol. 7, No. 2, e32688, 2012, https://doi.org/10.1371/journal.pone.0032688

17.Ridoutt, B. G., Eady, S. J., Sellahewa, J., Simons, L. and Bektash, R., Water footprinting at the Product Brand Level: Case Study and Future challenges, Journal of Cleaner Production, Vol. 17, No. 13, pp 1228-1235, 2009, https://doi.org/10.1016/j.jclepro.2009.03.002

18.Ridoutt, B. G. and Pfister, S., A new Water Footprint calculation Method integrating consumptive and degradative Water use into a single stand-alone weighted Indicator, The International Journal of Life Cycle Assessment, Vol. 18, No. 1, pp 204-207, 2013, https://doi.org/10.1007/s11367-012-0458-z

19.International Organization for Standardization (ISO), ISO 14046: Environmental Management-Water Footprint-Principles, Requirements, and Guidelines, International Organization for Standardization, Geneva, Switzerland, 2014.

20.Parparov, A., Hambright, K. D., Hakanson, L. and Ostapenia, A., Water Quality quantification: Basics and implementation, Hydrobiologia, Vol. 560, No. 1, pp 227-237, 2006, https://doi.org/10.1007/s10750-005-1642-y

21.Huang, J., Xu, C. C., Ridoutt, B. G., Liu, J. J., Zhang, H. L., Chen, F. and Li, Y., Water availability Footprint of Milk and Milk Products from large-scale Dairy production Systems in Northeast China, Journal of Cleaner Production, Vol. 79, pp 91-97, 2014, https://doi.org/10.1016/j.jclepro.2014.05.043

22.Abbasi, T. and Abbasi, S. A., Water Quality Indices, Elsevier, Oxford, UK, 2012, https://doi.org/10.1016/B978-0-444-54304-2.00016-6

23.Canadian Council of Ministers of the Environment (CCME), Canadian Water quality Guidelines for the protection of Aquatic Life, CCME Water Quality Index 1.0, User's Manual, Winnipeg, Canada, 2001, ceqg-rcqe.ccme.ca/download/en/138, [Accessed: 02-April-2017]

24.Canadian Council of Ministers of the Environment (CCME), Canadian Water Quality Guidelines for the protection of Aquatic Life, Self-specific Guidance, 2003, ceqg-rcqe.ccme.ca/download/en/221, [Accessed: 02-April-2017]

25.Alexakis, D., Tsihrintzis, V. A., Tsakiris, G. and Gikas, G. D., Suitability of Water Quality Indices for Application in Lakes in the Mediterranean, Water Resources Management, Vol. 30, No. 5, pp 1621-1633, 2016, https://doi.org/10.1007/s11269-016-1240-y

26.Hanslík, E., Marešová, D., Juranová, E. and Vlnas, R., Dependence of selected Water Quality Parameters on Flow Rates at River Sites in the Czech Republic, J. Sustain. Dev. Energy Water Environ. Syst., Vol. 4, No. 2, pp 127-140, 2016, https://doi.org/10.13044/j.sdewes.2016.04.0011

27.Čuček, L., Klemeš, J. J. and Kravanja, Z., A review of Footprint analysis Tools for monitoring impacts on sustainability, Journal of Cleaner Production, Vol. 34, pp 9-20, 2012, https://doi.org/10.1016/j.jclepro.2012.02.036

28.Jia, X. X., Varbanov, P. V., Walmsley, T. G. and Yan, Y., Water pollution impact assessment of Beijing from 2011 to 2015: Implication for degradation reduction, Chemical Engineering Transactions, Vol. 61, pp 1525-1530, 2017, https://doi.org/10.3303/CET1761252

29.Hoekstra, A. Y., Aldaya, M. M., Chapagain, A. K. and Mekonnen, M. M., The Water Footprint Assessment Manual: Setting the Global Standard, Routledge, Abingdon, Oxford, UK, 2012. 
30.Alcamo, J., Döll, P., Henrichs, T., Kaspar, F., Lehner, B., Rösch, T. and Siebert, S., Global estimates of Water withdrawals and availability under current and future "business-as-usual" Conditions, Hydrological Sciences Journal, Vol. 48, No. 3, pp 339-348, 2003, https://doi.org/10.1623/hysj.48.3.339.45278

31.Döll, P., Kaspar, F. and Lehner, B., A Global Hydrological Model for deriving Water availability Indicators: Model tuning and validation, Journal of Hydrology, Vol. 270, No. 1, pp 105-134, 2003, https://doi.org/10.1016/S0022-1694(02)00283-4

32.Huang, P., Jin, Y., Hou, D., Yu, J., Tu, D., Cao, Y. and Zhang, G., Online classification of Contaminants based on Multi-Classification support Vector Machine using Conventional Water Quality Sensors, Sensors, Vol. 17, No. 3, p 581, 2017, https://doi.org/10.3390/s17030581

33.Vieira, A. S., Humphrys, S., Beal, C. D. and Stewart, R. A., Optimising residential Water heating System performance to minimise Water-energy penalties, J. Sustain. Dev. Energy Water Environ. Syst., Vol. 4, No. 2, pp 161-172, 2016, https://doi.org/10.13044/j.sdewes.2016.04.0013

34.Pfister, S., Koehler, A. and Hellweg, S., Assessing the Environmental impacts of Freshwater consumption in LCA, Environmental Science \& Technology, Vol. 43, No. 11, pp 4098-4104, 2009, https://doi.org/10.1021/es802423e

35.State Environmental Protection Administration (SEPA) of China, Environmental Quality Standards for Surface Water (GB3838-2002), Research \& Report, Beijing, China, 2002.

36. State Environmental Protection Administration (SEPA) of China, Discharge Standard of Pollutants for Municipal Wastewater treatment Plant (GB18918-2002), Beijing, China, 2002.

37.Fan, Y. V., Varbanov, P. S., Klemeš, J. J. and Nemet, A., Process efficiency optimisation and integration for cleaner Production, Journal of Cleaner Production, Vol. 174, pp 177-183, 2018, https://doi.org/10.1016/j.jclepro.2017.10.325 